\title{
Copyright and Its Implications for 3D Created Datasets for Cultural Heritage Institutions
}

\author{
David Gillespie
}

\begin{abstract}
As museums and cultural institutions move towards openly sharing their collections via online platforms and other means, there is always a concern regarding the intellectual property rights of their works. This is becoming a bigger concern with the recent adoption of technologies that allow for 3D digital datasets to be created and shared online. These 3D datasets can be used for a range of different applications but there is a concern regarding the intellectual properties, as not only can they visualize the $3 \mathrm{D}$ cultural object but it can also be used to create an accurate replicate via 3D printing. This paper considers the intellectual implications for these created 3D datasets and questions whether it will impact the dissemination and sharing of these 3D datasets. Considering the evidence in this paper, it is suggested that it may have some impact but there are ways to mitigate any loss or damage.
\end{abstract}

Index Terms-Copyright, 3D cultural heritage datasets, Intellectual property.

\section{INTRODUCTION}

Cultural institutions such as museums are moving towards a paradigm of open content [1], where they wish to help enable education through openly sharing information freely to the general public. This information would be available within the museum or an online platform; allowing visitors to access their collections, exhibits, photographs, archive and other works. This adoption of open content has seen some success within the UK [2], [3], yet there are still some problems with regards to the dissemination and use of this content, the main concern being ownership of the IP. There are many licensing options available for openly using and the sharing of information such as the creative commons licenses [4] but a museum itself is fraught with IP perils. A museum is not considered an IP intensive industry but it is in the odd position of being both a licensor and licensee of IP [5]. There is a conflict between these different approaches which seem to be mutually exclusive, with little to no way of them coexisting together [1]. This comes under further complications when you consider three dimensional (3D) datasets of cultural heritage objects.

The last decade in cultural heritage has seen a large adoption of technologies that can accurately measure the physical world and create high resolution 3D digital models of cultural heritage objects or sites. The 3D dataset can also be used in range of applications as well as with rapid prototyping technologies such as computer numerically

Manuscript received July 25, 2015; revised October 20, 2015.

D. Gillespie is with the Centre of Digital Entertainment and the National Museums Liverpool, UK (e-mail: david.gillespie@ liverpoolmuseums.org.uk). controlled (CNC) machining or 3D printers to create replicas of the original artefact in a range of different materials and sizes [6]. With regards to the newly created 3D datasets, which include public domain works; should cultural institutions be allowed to obtain IP protection for these datasets, even if they are of public domain objects? What of objects that are utilitarian in purpose, would they be protected under IP laws? If so, what implications may this have? How will it impact the dissemination and sharing of information?

This paper is an attempt to answer these questions, which are currently a big concern for cultural institutions. This paper will review IP laws within the UK as to discover if it is possible to claim IP protection on a cultural heritage dataset that has been scanned. The paper will then discuss if any new works from the dataset would warrant IP protection. The last section discusses if this actually impacts the dissemination and sharing of $3 \mathrm{D}$ datasets.

\section{INTELLECTUAL PROPERTY WITHIN UK LAW}

In the UK, IP is an umbrella term that covers primarily Copyright, Patents, Design and Trademark, which confer to the author of the work certain exclusive rights regarding how the work may be used and distributed for a set amount of time. These rights also allow the author to dictate how others may use their work and it is also possible to transfer these rights to other individuals or corporations with the exception of moral rights within copyright [7].

Considering cultural heritage institutions, it is most likely that Copyright laws will have the most impact regarding 3D datasets. The other classes of IP law cover patent law, and trademark law, where it is possible to infringe the rights of the IP holder with unlawful use. However, patent law is not applicable, as it covers an invention that is "new, involves an inventive step and is capable of industrial application" [8]. Trademark IP laws are also just as unlikely to apply, as it covers the broad scope of signs, design or graphical representations that identifies a product or service from a particular source from others of the same type [9]. The only issue that could possibly arise would be the use of a trademark being embedded within a 3D dataset and sold without permission of the trademark holder. Design Law covers the visual appearance of products for industrious design. It is an extremely complex area of law and lies out of the scope of this paper but is discussed to great depth by Dinusha Mendis [10].

\section{COPYRIGHT}

Copyright within the UK is a right conferred to an author 
to protect the expression of their idea, if it is original and has needed substantial degree of skill to create. This covers artistic, literary, dramatic, musical, films, sound recordings, broadcasts and published editions (typographical works). From the moment of its creation, copyright subsists in the new work [11] and will do so for the life of the author and 70 years after their death. The author may also sue for damages if an individual or corporation has used the work without permission or a license from the author. There are exceptions within UK law for fair use, which include: private research or personal study, education, criticism, reviewing or reporting [12] and more recently parody [13].

Copyright can not exist in a work that is within the public domain or for objects that are considered useful. This raises concerns for 3D datasets created from objects within a cultural institutions collections, especially a piece is within the public domain, a utilitarian object or a TCE. Works that are within the public domain can be exploited by anyone for free without permission or license. However, this is a contentious issue currently as institutions may generate revenue though worldwide licensing agreements for the use of photographs of paintings and other artworks that clearly are in the public domain [14], [15].

This is further complicated when you consider a 3D dataset, which could be used to recreate an accurate replica of the physical object. Under current UK copyright in the Copyright, Design and Patents Act 1988 (CDPA), a work warrants copyright if it is deemed to be original but has also been created through a degree of labour and have both skill and judgement applied during the creation of the expression of the work [16]. Copyright does not exist in a piece that was created through an entirely mechanical process or is a slavish reproduction [17]. This would apply then that any images taken of a work that was within the public domain, to be a "slavish" reproduction and not warrant copyright protection.

The USA court case of Bridgeman Art library, Ltd. V. Corel Corp [17] addressed the use of 2D photographs of works within the public domain. The case held the decision that the digitisation of works within the public domain did not warrant new copyright as the work was not original and a slavish reproduction of the original public domain art. Even if a substantial amount of skill and effort was used in the reproduction of the piece to a new medium, as noted in a previous case "Sweat of the Brow" alone is not the "creative spark" which is the sine qua non of originality" [18]. The court did argue that even under UK Copyright law; copyright would not subsist in the new work. However, the outcome of the case is not binding in the UK, but the significance of this case has led to many debates regarding the decision. Within the UK, the Museums Copyright Group commissioned a report on the decision of the case [19] and a seminar at the Queen Mary University of London where in attendance art professionals, IP lawyers and other creative individuals decided that the decision should be reversed [20]. However, this may have been more recently contested within the UK with cases such as the Temple Island V. New English Teas and Nicholas John Houghton, where the originality for copyright in photography is defined where "taking of the photograph leaves ample room for an individual arrangement" [21], where images of public domain paintings and art could be considered slavish reproductions with no room for individual arrangements and warrant no copyright protection.

However, in the UK though the CDPA states that copyright will be granted if the work is original and considerable skill and judgment was used in the creation of the expression, courts have not adopted a literal reading of the law. UK courts have adopted a stance that if a reasonable amount of skill and judgement in the creation of an expression is acceptable to warrant copyright protection [22]. Yet the copyright implications of scanning 3D cultural heritage objects that lie within the public domain are ambiguous. Using the reasoning of Temple Island vs. New English Teas, it should not be possible to get copyright protection in the design document that is created. The idea of granting copyright protection to recreated artistic works due to the skill and judgment that take place to create the file is supported by Ong [23]. He justifies that it could be in the public's best interest for replicas to be recreated of works that have are of cultural importance or are not readily available to the public. This is further supported by cases of Antiquesportfolio [24] and Painer [25]. The case of Antiquesportfolio held that there can be copyright in the protection of photographs of 3D antiques, due to the angle of the camera, lighting and camera focus which led to exhibiting features of the antique such as colour and details on the item. Due to the skill being shown in these photographs, it was concluded that it did warrant copyright protection even though these skills were at a basic level [24]. A similar conclusion was reached in the Painer case, which focused on the copyright protection for works based on reality such as portrait photos [25].

The decision of the Bridgeman Art library, Ltd. V. Corel Corp has been applied to the 3D recreation of a physical object in the US court case of Meshwerks, Inc. v. Toyota Motor Sales [26], where it was decided that a replication would not warrant copyright. However, as pointed out by Michael Weinberg [27], that this may change in USA law if it grows to recognise the artistry in the artistic process for the creation of a 3D dataset, which is recognised in photography [28]. During the capture and creation of the digital design file from either scanning or photogrammetry, it could be argued that the skill and creativity shown, in selecting certain views, lighting conditions and processing the data, and in its creation would make it an "intellectual creation of the author reflecting his personality and expressing his free and creative choices" [25]. Taking this into account, the copyright protection of a created dataset is still rather ambiguous and it will need to be settled with a future court case within the UK or the EU.

However, it is clear that if a 3D dataset was created from an artistic work that is still protected by copyright, it would be considered a derivative work of the original and subsequently would infringe copyright [29]. However, Bradshaw [30] identified 2 possible cases where copyright may be eroded for a physical copy. The definition of the object produced and the digital file as a design file.

\section{A. Definition of an Object}

Copyright may subsist in the digital file, and its subsequent 
derivative works including 3D printed models. However, there is an issue with the classification of the $3 \mathrm{D}$ printed object in itself. It could be assumed that as the dataset is based on an artwork, it could be defined as a sculpture as defined in section 4 of the CDPA 1988 [31]. Yet within court cases the definition of a sculpture, has always been a some what difficult area to define, with various rulings attempting to clarify what a sculpture is [30]. This led to a judgement in Lucasfilm Ltd. \& Ors v Ainsworht Anor [32] that a work would qualify as a sculpture if the object had an "intrinsic quality of being intended to be enjoyed as a visual thing" even if it had other purposes [32], LucasFilms ltd. Tried to assert that the original clay model of the Storm Trooper helmet would be classified as an artistic work under the CDPA 1988 [31]. However, the courts upheld that the clay model had a utilitarian purpose, as it is a helmet first and foremost, therefore there could be no copyright infringement under section 51 and 52 of the CDPA [32]-[34]. While artistic works will be protected, this ruling lends itself to $3 \mathrm{D}$ printing of utilitarian objects and as section 51 of CDPA states:

1) It is not an infringement of any copyright in a design document or model recording or embodying a design for anything other than an artistic work or a typeface to make an article to the design or to copy an article made to the design.

2) Nor is it an infringement of the copyright to issue to the public, or include in a film, anything the making of which was, by virtue of subsection 1), not an infringement of that copyright. [33]"

In Section 51 of the CDPA 1988 a design document is specified as:

"Design document" means any record of a design, whether in the form of a drawing, a written description, a photograph, data stored in a computer or otherwise [33].

Where in section 51, an item produced via a design document will not result in copyright infringement [33]. This was the case in Lucasfilm Ltd. \& Ors v Ainsworht Anor, where the original artwork for the helmets was designated a design document for the creation of the 3D helmets. This would raise many implications for IP and is answered by Bradshaw et al. [30], but as stated in section 51, artistic works are exempt from this protection. However, in section 52 of the CDPA, if artistic works are used for mass production for the generation of revenue, the copyright on the work would be severely reduced to 25 years [34].

\section{B. Other Protections}

While a museum may be able to have ownership of the 3D dataset, it is still expected to use the digital file to share the knowledge and use of for educational purposes in a public forum. However, as explained by Koller et al. [35] a museum may be afraid too, as they would lose control over how the object would be represented and there is a chance of the model being pirated if the model was disseminated over the internet [35]. To combat unauthorised distribution there are tools available which are codified in the US Digital Millennium Copyright Act 1998 [36]. Michael Weinberg explains briefly how this is an acceptable tool to stop the online distribution of infringing content [27], but it doesn't allow a museum to maintain control over its IP fully.

Also of note is the ownership of copyright of the 3D dataset. As described in the CDPA section 11, the Author of the work would be the copyright owner not the commissioning party [37]. The institutions would need to secure all rights to the new files created via a contract assigning all rights to the cultural institutions or acquiring a license to use the 3D file.

A final important fact to note is that many museums and cultural institutes within the UK can be subject to a Freedom of Information Act request [28]. This allows a member of public to make a request for and to use certain information held by a public institution, body or department. If a member of public makes a request to the department, they are entitled to:

a) To be informed in writing by the public authority whether it holds information of the description specified in the request, and,

b) If that is the case to have that information communicated to him. [38]"

So one would assume that the $3 \mathrm{D}$ dataset would be available under a Freedom of Information request, but this is not the case. There are exemptions and clauses that protect the public body to decline the request for information, two clauses that may be used to protect the datasets are:

Commercial interests:

"Information is exempt information if its disclosure under this Act would, or would be likely to;

prejudice the commercial interests of any person (including the public authority holding it). [39]"

Law Enforcement:

"The purpose of protecting the property of public authorities from loss or misapplication [40]"

This same protection could be applied to stop the general public who wish to attempt to create a $3 \mathrm{D}$ dataset from a sculpture or object. The museum is not required to grant that person access to that work for documentation, and could ask the person to leave. This can also be applied to both public and private institutions.

\section{DOES THIS IMPACT THE DisSEMINATION OF 3D Cultural Heritage ConTENT?}

While the legal clarity surrounding IP protection for these datasets is ambiguous, it opens up new areas of innovation, dissemination and potential revenue for cultural institutions. There is an ever growing market for this type of $3 \mathrm{D}$ content especially in 3D printing, which was valued at $\$ 2.2$ billion by Wohlers Associates [41] and this is figure is still expected to grow in the coming years. Yet, due to the high value these datasets possibly command, it is worth considering how these datasets can be protected and possibly monetized. Especially when considering sharing this information on the internet, where duplicating the dataset and sharing it with other users is extremely easy without informing the original owner. There may also be concerns regarding piracy and loss of control of data, yet it should be considered that the gains of openly sharing these collections will always out weigh the perceived loss [14]. 
The possibilities and opportunities that a 3D data set offer, will invariably attract users who wish may to download or replicate one of the datasets protected by IP law. As such there are methods that can be used for the protection of the datasets, wither this is in partnership with a $3^{\text {rd }}$ party platform for $3 \mathrm{D}$ printing or through the use of a licensing for the actual dataset file. There are systems that have been developed for interaction and visualisation of cultural heritage models, without the user downloading the actual dataset.

Koller et al. [42], [43] created a visualisation system called ScanView to enable users to interact with 3D models created during the Digital Michelangelo project [44] while protecting the 3D dataset. They created a portal that would allow users to interact with a low resolution model, where they used a combination of technique such as remote rendering of the full resolution 3D dataset with subtle distortions to the model. This closed designed system meant no datasets where downloaded and it wasn't possible to recreate a dataset from extracted images. Yet while the system was acceptable, the use of the distortion and noise distracted the end user from the experience of interacting with a dataset [45] and hindered in some instances of interaction. Similar solutions have been launched within other industries but it is now possible to use the internet to disseminate and engage with 3D models directly [46], [47]. The internet also allows for a subtle form of protection commonly referred to an always "always on" system that requires users to connect to a server to authenticate the use of the work [48], [49]. While this approach is not as restrictive as the likes of ScanView, it presents unique problems especially when content is only available when the server is online [50], [51].

There is an alternative to these types of systems, which is the adoption of a traditional licensing, which is commonly used for photographs of cultural content. This approach allows a cultural institution the possibility of generating revenue through licensing agreements or allowing open access through a Creative Commons license. There have been successful attempts at the sharing and printing of $3 \mathrm{D}$ content, both from video games such as Second Life [52] and even more successfully by FigurePrints [53]. Where they obtained a license from Blizzard, which allowed them to print gamers in game characters from World of Warcraft in full colour and have them delivered to the customer [53]. There has even been some success with cultural heritage institutions using online platforms to disseminate 3D content such as The British Museum using SketchFab [54] and The Metropolitan Museum of Art [55]; allowing users to download low resolution datasets, and print these objects from either museums collection under a creative commons license.

The use of licensing has advantages over of a closed loop system, which in some cases has been shown to actually lead consumers to piracy, as they feel victimised by restrictions and the lack of freedom to use the content for other purposes [56]. There is other research that points to the ineffectiveness of these systems to deter piracy and can actually drive users to restriction free content [57]. A bigger surprise is that companies that have removed restrictions on their content have not seen a loss of revenue due to piracy [58] and in some cases actually increased profit [59].

While many institutions may worry about piracy and the loss of control over their works or 3D datasets, there have been many debates regarding monetary damage from illegally sharing files. In 2011 Motion Pictures Association of America (MPAA) claimed that the US economy lost \$58 billion due to piracy [60], but the figure itself was extremely exaggerated due to issues such as counting every illegal download as a lost sale [61] and assuming adults would buy an addition 200 DVDs a year [62]. This topic is highly contentious both in the estimations of damage and how to effectively combat piracy but it appears to have little effect on $3 \mathrm{D}$ content.

One of the largest and most infamous online platforms for the distribution of both legal and illegal content is the Pirate Bay. This platform has been blocked in the UK and other countries due to allowing users to share illegal copyrighted files. In January of 2012 the Pirate Bay introduced "Physibles", a section to share 3D datasets for 3D printing [63]. Yet the section contains very few files in comparison to the large amount of torrents available to download [64]. With such a low number, it can only be assumed there is not a lot of interest in either uploading or downloading of 3D content from these types of sites.

It's more likely for 3D content to be hosted on 3D online platforms such as Sketchpad or Thingiverse, which provide an interesting insight in to their users, the most popular categories for 3D models and the impact of sharing 3D content. These sites are legal file sharing platforms that offer the ability to interact with the 3D content in the browser and encourage the sharing of $3 \mathrm{D}$ content under a creative commons license as well [65]. These sites host a vast range of 3D content from spare parts, games characters, cultural heritage items and an assortment of other categories. As well as these platforms, there are others that allow users to buy 3D datasets to print at home that have been created by designers, companies or amateurs. One of the biggest sites is Shapeways, which allows designers and companies to create shops on their platform to sell their designs, which are then printed by Shapeways in a range of different materials. This secures the access to the digital file, as it is only shared with Shapeways and but also protecting users who may get a defective purchase where blame would be laid with Shapeways. These sites also take on the burden of possible copyright infringement away from the designer or company. If shapeways was to print a piece that was infringing someone's copyright, it is likely that Shapeways would be the infringer for creating a derivative work from the original. This has forced Shapeways to check for IP infringement before proceeding to print any work, and if any infringement is suspected they will not print the piece [66]. This policy is being used by other similar platforms, although it can be subject to human error it is reducing the amount of infringement that is taking place on these sites.

\section{CONCLUSION}

The creation of extremely accurate data sets of cultural heritage objects has been very beneficial revealing hidden information and allowing users to interact with these objects in new and exciting ways. However, with these benefits issues have been raised concerning the IP issues while 
increasing the access to these 3D datasets. This is becoming increasingly more important as the technology to scan and replicate objects is heading towards the domestic market.

This paper has attempted to explain how copyright under UK law may be applied to a cultural heritage object, even if it lies within the public domain. As discussed in this paper, it should be possible to acquire copyright with scanning but a test case would be needed to test this hypothesis within the EU or UK. If copyright subsisted in the digital files, any derivative works that would be created would also warrant copyright protection unless it was of a utilitarian object or exempt for fair use.

This paper has also highlighted the possible ways to disseminate and share the datasets via websites through the use of licenses or a closed system. Where it would be possible to openly allow the datasets to be shared openly through a Creative Commons licenses and possibly generate revenue though various business options including 3D printing. Yet it should not be under taken lightly as there will be risks involved and possible repercussions for the cultural institution. Though there are risks involved, the benefits of sharing cultural heritage content will always outweigh the risks.

\section{REFERENCES}

[1] NMC. (2012). Horizon report: 2012 museum edition. The New Media Consortium. [Online]. Available: http://www.nmc.org/pdf/2012-horizon-report-museum.pdf

[2] Google. (2011). Google art project. [Online]. Available: http://en.wikipedia.org/wiki/Google_Art_Project

[3] British Library. (2013). British library - Digitized manuscripts. [Online]. Available: http://www.bl.uk/manuscripts/About.aspx

[4] Creative commons. (2013). About the license. [Online]. Available: http://creativecommons.org/licenses/

[5] European Patens Office and Office for Internal Harmonization in the Internal Market. (2013). Intellectual property rights intensive industries: Contribution to economic performance and employment in the European Union Industry-Level Analysis Report. [Online]. Available: http://documents.epo.org/projects/babylon/eponet.nsf/0/8E1E34349D 4546C3C1257BF300343D8B/\$File/ip_intensive_industries_en.pdf

[6] A. L. Pensée, '3D laser scanning in 3D documentation and digital reconstruction of cultural heritage," JISC 3D Visualisation in the Arts Network, Bulletin, 2008.

[7] Intellectual Property Office. (2013). Moral rights. [Online]. Available: http://www.ipo.gov.uk/types/copy/c-otherprotect/c-moralrights.htm

[8] Patents Act 1977, section.1

[9] Trade Marks Act 1994, section 1(1).

[10] D. Mendis, '"The clone wars": Episode I', European Intellectual Property Review, vol. 35, no. 3, pp. 155, Supplemental Index, 2013.

[11] Berne Convention for the Protection of Literary and Artistic Works, Paris Text 1971.

[12] N. Korn. (2005). Guide to intellectual property rights and other legal issues. [Online]. Available: http://www.minervaeurope.org/publications/Guideipr1_0.pdf

[13] Intellectual property office. The copyright and rights in performances (quotation and parody) regulations 2014. [Online]. Available: http://www.legislation.gov.uk/ukdsi/2014/9780111112717

[14] K. Kelly, Images of Works of Art in Museum Collections: The Experience of Open Access, A Study of 11 Museums, The Andrew W. Mellon Foundation, 2013.

[15] R. E. Pantalony, A WIPO Guide on Managing Intellectual Property for Museums, 2013.

[16] Copyright, Designs and Patents Act, 1988. Section 1.

[17] Bridgeman Art library, Ltd. V. Corel Corp [2000], 36 F. Supp. 2d 191 (S.D.N.Y. 1999)

[18] Feist Publications, Inc. v. Rural Telephone Service Co. [1991] 499 U.S. 340

[19] Museum copyright group. (2013). Copyright in photographs of works of art. [Online]. Available: http://museumscopyright.org.uk/resources/articles/bridgeman/
[20] Target wire. (2009). Conference on copyright law in the visual arts puts Bridgeman $\mathrm{v}$ Corel back in the spotlight. [Online]. Available: http://www.targetwire.com/targetwire/2007/05/17/po180/po180_uk.ht $\mathrm{ml}$

[21] Temple Island Collections Ltd v New English Teas Ltd \& Anor [2012] EWPCC 1

[22] Express Newspapers v Liverpool Daily Post \& Echo Plc. [1985] FSR 306

[23] B. Ong, 'Originality from copying: Fitting recreative works into the copyright universe," Intellectual Property Quarterly, no. 2, pp. 165-191, 2010.

[24] Antiquesportfolio.com plc v Rodney Fitch \& Co Ltd [2001] FSR 345

[25] P. S. V. GmbH, A. A. G. Springer, Süddeutsche Zeitung GmbH, Spiegel-Verlag Rudolf Augstein GmbH \& Co. KG, Verlag M. DuMont Schauberg Expedition der Kölnischen Zeitung GmbH \& Co. KG [2012] ECDR 6

[26] Meshwerks, Inc. v. Toyota Motor Sales USA Inc [2008] 528 F.3D 1258 (10th Cir.)

[27] M. Weinberg. (2013). What's the Deal with Copyright and 3D printing? Public Knowledge. [Online]. Available: http://www.publicknowledge.org/files/What's\%20the\%20Deal\%20wit h\%20Copyright_\%20Final\%20version2.pdf

[28] Burrow-Giles Lithographic Co. v. Sarony [1884] 111 U.S 53.

[29] Copyright, Designs and Patents Act, 1988. Section 17.

[30] Bradshaw, S., Bowyer, A. and Haufe, P., 2010. The Intellectual Property Implications of Low cost 3D Printing. Scripted 7

[31] Copyright, Designs and Patents Act, 1988. Section 4.

[32] Lucasfilm Ltd. \& Ors v Ainsworht Anor [2011] UKSC 39.

[33] Copyright, Designs and Patents Act, 1988. Section 51.

[34] Copyright, Designs and Patents Act, 1988. Section 52.

[35] D. Koller, M. Turitzin, M. Levoy, M. Tarini, G. Croccia, P. Cignoni, and R. Scopigno, Protected interactive 3D graphics via remote rendering, Acm Transactions On Graphics, vol. 23, no. 3, pp. 695-703.

[36] Digital Millennium Copyright Act, 1998

[37] Copyright, Designs and Patents Act, 1988, Section 11.

[38] Freedom of Information Act, 2000,Section 1

[39] Freedom of Information Act, 2000,Section Commercial interest.

[40] Freedom of Information Act, 2000,Section Law Enforcement.

[41] Wholers Associates, 'Wholers Report 2013: Additive Manufacturing and 3D printing State of the industry,' Annual Worldwide Progress Report, 2013.

[42] D. Koller and M. Levoy, '2005 Protecting 3d graphics content, Communications of the ACM, vol. 48, pp. 74 .

[43] D. Koller, B. Frischer, and G. Humphreys, 'Research challenges for digital archives of 3D cultural heritage models,' ACM Journal on Computing \& Cultural Heritage, vol. 2, no. 3, pp. 1, 2009.

[44] M. Levoy, K. Pulli, B. Curless, S. Rusinkiewicz, D. Koller, L. Pereira, M. Ginzton, S. Anderson, J. Davis, and J. Ginsberg, 'The Digital Michelangelo Project: 3D Scanning of Large Statues,' Addison-Wesley, pp. 131-144, 2000.

[45] J. Zhu, 'Quantifying Usability in Secure Graphics: Assessing the User Costs of Protecting 3D Content,' vol. 1, pp. 1-6, 2008.

[46] Google. (2013). Chrome Experiments. [Online]. Available: Http://www.chromeexperiments.com/

[47] J. Behr, Y. Jung, J. Keil, T. Drevensek, M. Zoellner, P. Eschler, and D. Fellner, 'A scalable architecture for the HTML5/X3D integration model X3DOM,' Proceedings of the 15th International Conference on Web 3D Technology, Los Angeles, California: ACM, 2010.

[48] H. A. Deveci, 'Can hyperlinks and digital rights management secure affordable access to information?' Computer Law \& Security Review, vol. 28, no. 6, pp. 651-661, 2012.

[49] E. K. Y. Jung, R. A. Levien, R. A. Lord, M. A. Malamud, J. D. Rinaldo, C. T. Tegreene, and L. L. Wood, Manufacturing Control System, US Patent 8,286,236, Intellectual Venture, 2012.

[50] E. Kain. EA Admits SimCity Could Have Run Offline. [Online] Available:

http://www.forbes.com/sites/erikkain/2013/03/17/ea-admits-simcity-c ould-have-run-offline-went-against-developers-vision/

[51] J. Walker. (2012). Ubisoft Scrapping Always-on DRM for PC Games. [Online]. Available: http://www.rockpapershotgun.com/2012/09/05/ ubisoft-scrapping-always-on-drm-for-pc-games/

[52] P. Reeves, C. Tuck, and R. Hague, Additive Manufacturing for Mass Customization' in Mass Customization, London, UK: Springer-Verlag, 2011, chapter 13.

[53] FigurePrints. FAQ. [Online]. Available: http://www.figureprints.com/wow/Help/FAQ.aspx 
[54] The British Museum. [2014]. Night at the museum: Fact vs Fiction. [Online]. Available: http://www.britishmuseum.org/visiting/family _visits/night_at_the_museum/fact_vs_fiction.aspx

[55] J. Terrassa. (2012). Met - 3D: The Museums First 3D Scanning and Printing Hackathon. [Online]. Available: Http://www.metmuseum.org/ about-the-museum/now-at-the-met/features/2012/hackathon

[56] D. Vernik, D. Purohit, and P. Desai, 'Music Downloads and the Flip Side of Digital Rights Management,' Marketing Science, vol. 30, no. 6 , pp. 1011-1027, 2011

[57] H. Sudler, 'Effectiveness of anti-piracy technology: Finding appropriate solutions for evolving online piracy,' Business Horizons, vol. 56, no. 2, pp. 149-157, 2013.

[58] J. Crisp. (2013). One Year Later, the Results of Tor Books UK Going DRM-Free. [Online]. Available: http://www.tor.com/blogs/2013/04/ tor-books-uk-drm-free-one-year-later

[59] L. Zhang. (November 2014). Intellectual property strategy and the long tail: Evidence from the recorded music industry. [Online]. Available: http://inside.rotman.utoronto.ca/laurinazhang/files/2013/12/jmp_nov2 5.pdf

[60] Motion Pictures Association of America. (2011). MPAA Infographic. [online]. Available: http://www.scribd.com/doc/62848402/mpaa-infographic

[61] Moses, A. (2011). Piracy, are we being conned? [Online]. Available: http://www.smh.com.au/technology/technology-news/piracy-are-we-b eing-conned-20110322-1c4cs.html
[62] S. L. Wilson. (2011). Box Office Records and Whining Twatwaffles of the MPAA. [Online]. Available: http://www.pajiba.com/trade_news/ box-office-records-and-whining-twatwaffles-of-the-mpaa.php

[63] K. Scott. (January 2012). The Pirate Bay Adds 'Physibles' 3D Printing Category. [Online]. Available: http://www.wired.co.uk/news/archive/ 2012-01/24/pirate-bay-introduces-physibles

[64] Softpedia. (August 2014) The PirateBay reaches 10 millionth torrent milestone. [Online]. Available: http://news.softpedia.com/news/The -PirateBay-Reaches-10-Millionth-Torrent-Milestone-438660.shtml

[65] Thingiverse. (2015). What is Thingiverse? [Online]. Available: http://www.thingiverse.com/about

[66] Shapeways. Shapeways Content Policy and Notice Takedown Procedure. [Online].

Available: http://www.shapeways.com/legal/content_policy

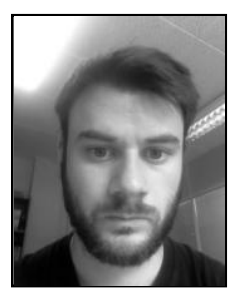

David Gillespie received the BSc degree in digital interaction design from Dundee University in 2011 $\mathrm{He}$ is now pursuing his EngD degree with the Centre for Digital Entertainment with Bournemouth University while being on a research placement with the National Museums Liverpool. 